\title{
FECUNDITY, DEVELOPMENT AND NATURAL HISTORY OF MERONERA VENUSTULA (ERICHSON) (COLEOPTERA: STAPHYLINIDAE: ALEOCHARINAE)*
}

\author{
By James S. Ashe \\ Department of Zoology, \\ Field Museum of Natural History, \\ Roosevelt Road at Lake Shore Drive, \\ Chicago, Illinois 60605
}

\section{INTRODUCTION}

Knowledge of habits of the large, diverse and taxonomically difficult staphylinid subfamily Aleocharinae is very incomplete (Ashe 1981, 1984, Ashe and Watrous 1984). It has been generally assumed that, except for aberrent groups such as the fungus-feeding Gyrophaenina (Ashe 1984), aleocharines as a whole are mostly generalist predators (Fenyes 1918-21). Yet the diversity of aleocharines and their abundance in many habitats suggests that other means of resource use may have been evolutionarily explored. A greater understanding of the diversity of ways that aleocharines use the habitat, the distribution of use patterns and relationships of these patterns to phylogenetic relationships among taxa is essential for clarifying major evolutionary features within this subfamily.

This paper represents a contribution toward that knowledge. It developed from attempts to keep a variety of aleocharine adults in the laboratory, and to encourage them to lay eggs with the hope of obtaining identified larvae which could be compared with aleocharine larvae frequently encountered in he field. The procedures were particularly effective for specimens of Meronera venustula (Erichson) (Tribe Tachyusini).

The genus Meronera, described by Sharp (1887) from Central America, includes 9 species (Fenyes 1918-21). Most described species occur in Central or South America, and the group appears to be primarily Neotropical in distribution. In America north of Mexico, 1 species, Meronera venustula (Erichson) [including 2 species described by Casey (1906) and synonomized by Fenyes (1918-21)] is

*Manuscript received by the editor March 26, 1985. 
known. Little information on biology, habitat or life history of any member of Meronera is available.

Meronera venustula (Erichson 1840) is distributed throughout the eastern half of the United States. Only Blatchley (1910) provides sketchy notes on its biology. He noted that specimens of $M$. venustula were collected by sifting vegetable debris, and stated that specimens overwinter as hibernating adults, though he gives no data to support this statement.

Adults of Meronera venustula, collected in the early spring, were easily maintained in the laboratory. Though cultures were maintained primarily to provide correct larval associations, observations of such colonies has provided considerable information about feeding habits, fecundity, longevity and developmental times of adults and immatures. It is recognized that such observations under artificial conditions may not accurately reflect life history characteristics in natural situations. However, they are suggestive and provide a first approximation to understanding the natural history and ecology of these aleocharines.

In this paper, I provide information about the feeding habits, egg-laying rate, immature developmental times and longevity of adults of Meronera venustula based on colonies maintained in the laboratory. Late instar larvae are described and illustrations of distinctive features are provided.

\section{Materials AND Methods}

Adults of Meronera venustula were collected by sifting dead grasses and sedges at the edge of a partially dried slough on April 26, 1984 in Palos Hills, Cook Co., Illinois. Sifted material was transferred to a white enameled pan, and adults were aspirated and transferred to snap-top glass vials filled with crushed fresh leaves. Survival of adults during return to the laboratory is very good under these circumstances. Sifted material was returned to the laboratory in plastic bags, and berlesed to determine relative proportions of different aleocharine species and the presence and type of larvae in the sample. No aleocharine larvae were found, suggesting that aleocharines had not begun oviposition at this time of year. A similar sample from the same locality and microhabitat collected on May 3, 1984 also contained adult $M$. venustula but no larvae. 
Litter in the forest surrounding the slough where specimens of $M$. venustula were collected did not yield any specimens of this species after similar collecting techniques.

Adults were returned to the laboratory and placed in petri dishes with a uniform layer of about $0.5 \mathrm{~cm}$ of plaster of paris in the bottom. Plaster of paris was moistened whenever it became dry by adding drops of water directly to the surface. Small pieces of Purina Puppy Chow ${ }^{\circledR}$ were moistened and provided as food for the beetles and were readily accepted. A few short strips of paper toweling were placed in the dish to provide concealment for adults and as substrate for oviposition. Fungus began to grow on the food within 24 hours. Fungus covered food was replaced daily with fresh food except when fungus feeding occurred. In this latter instance food was changed every 3 days.

Cultures of adults were examined daily for the presence of eggs and to monitor general health of the colony. Eggs were transferred to similar petri dishes, and larvae were fed and maintained in a similar way to adults. Selected eggs and resulting larvae were periodically monitored to determine developmental rates.

All cultures were maintained at room temperature. This temperature generally varied between $22^{\circ}$ and $25^{\circ} \mathrm{C}$, but fluctuated widely, occasionally reaching $29^{\circ} \mathrm{C}$ in the latter stages of the study. These occasional high temperatures may be responsible for the relatively slight success in rearing larvae to maturity, especially in latter stages of the project. However, the possibility that a buildup of pathogens in the cultures could cause similar mortality cannot be eliminated.

Mature larvae were transferred to vials of finely ground peat moss for pupation.

Selected adults and larvae of each instar were preserved, cleared in Nesbitt's solution and mounted on microscope slides in Hoyer's medium for study. Detailed studies of slide mounted specimens were carried out with a Wild M-20 compound microscope. Drawings were facilitated by use of a drawing tube attachment.

\section{BEHAVIOR}

Feeding was regularly observed, and both adults and larvae readily accepted Purina Puppy Chow ${ }^{\circledR}$ as food and appeared to survive well on it. An unexpected observation was that at least adults and 
probably larvae actively fed on the fungus mycelium infesting the food particles. Normally, within 24 hours fungus would invade the food substrate. This was a serious problem in most cultures of aleocharines since fungus mycelium would quickly spread throughout the petri dish, commonly entangling the adults or otherwise restricting their activities. This problem did not become serious in colonies of $M$. venustula. In these cultures the food became covered by uniform velvety pile of fine short fungus fibers, but these did not develop into the large fibers of fungus mycelium common in other cultures. Adult $M$. venustula were often observed grazing in numbers on fibers of the pilose fungus growth on food particles. These observations suggest that growth of the fungus was restricted by continual grazing of the beetles. This hypothesis is further supported by the fact that as adults of the colony began to age, toward the middle of June, and become less vigorous and many had died (Figure 1), fungus on the food began to form a more normal mass of long mycelial fibers. This was first noticed on June 11, after egg laying had ceased.

Comparable observations for larvae are not available. Larvae were kept in individual dishes and could not have the same effect on fungus growth as could the more numerous adults. However, fungus mycelium and spores, along with bits of food substrate, were found in the guts of many slide mounted larvae. It is not possible to eliminate the possibility that the fungus was ingested accidently while feeding on the more normal food. However, this seems unlikely in view of the large amount of fungus in the guts of many larvae.

Mating was commonly observed in the petri dishes and was typical of that described for other aleocharine staphylinids (Peschke 1976, Ashe 1981). The relatively low proportion of males collected and included in the cultures (Figure 1) appears to reflect a natural unequal sex ratio present in early spring when collections were made.

A behavior which may be associated with mating activity but which appeared to be of much more general occurrence was regularly observed in cultures of $M$. venustula. If one individual crawled across or touched another, it often initiated a short, very rapid chase, with the mouthparts of the following beetle at the apex of the abdomen of the leader. This chase would continue for distances of 
$1.0-2.5 \mathrm{~cm}$. Often each beetle would try to bend its' mouthparts to the apex of the other's abdomen. In this instance, the two beetles would run rapidly in a very tight circle. The reason for this activity is not known, but it seemed to occur without discrimination as to sex. The virtually invariant application of mouthparts to the apex of the abdomen rather than to other parts of the beetle suggests that important glandular secretions may be produced there, though this possibility obviously requires additional verification.

\section{Egg Laying, Fecundity and Adult Longevity}

Egg laying was not observed. Therefore, it was not possible to gain any information bearing on Topp's (1975) suggestion that aleocharine females take their eggs in their mandibles and distribute them within the litter or other substrate. He based this on observations of members of the Bolitocharini (1973) and Athetini (1971, 1975b). Eggs of $M$. venustula were most commonly found on strips of paper or occasionally on bits of vegetation placed in the petri dish. However, they were also found unconcealed on the plaster or on particles of fungus covered food. Fungus surrounding the eggs did not cause any noticable ill effects. There did not appear to be any difference in hatching success or survival of eggs, whether they were on plaster, paper or fungus covered food. No instance of egg cannibalism was observed even if eggs were occasionally left in association with adults for extended periods and adults were observed to come in contact with or crawl over eggs.

Daily production of eggs over the life of the colony is shown in Figure 1. No eggs were laid during the first 20 days from the time adults were taken in the field. During this period adults were active, feeding and apparently healthy (no mortality which could be associated with trama of collection occurred after the first 2 days of the colony). This may represent a normal preoviposition period for $M$. venustula. This supposition is strengthened by the fact that no larvae of $M$. venustula were found in berlesed litter samples on April 26 or on May 3, suggesting that egg laying had not yet occurred under natural conditions, though adults were common and active. It is not possible to surmize how long adults had been active before they were collected. Therefore, preoviposition period of $M$. venustula appears to be at least 20 days at room temperature, though it may be longer under natural conditions. 


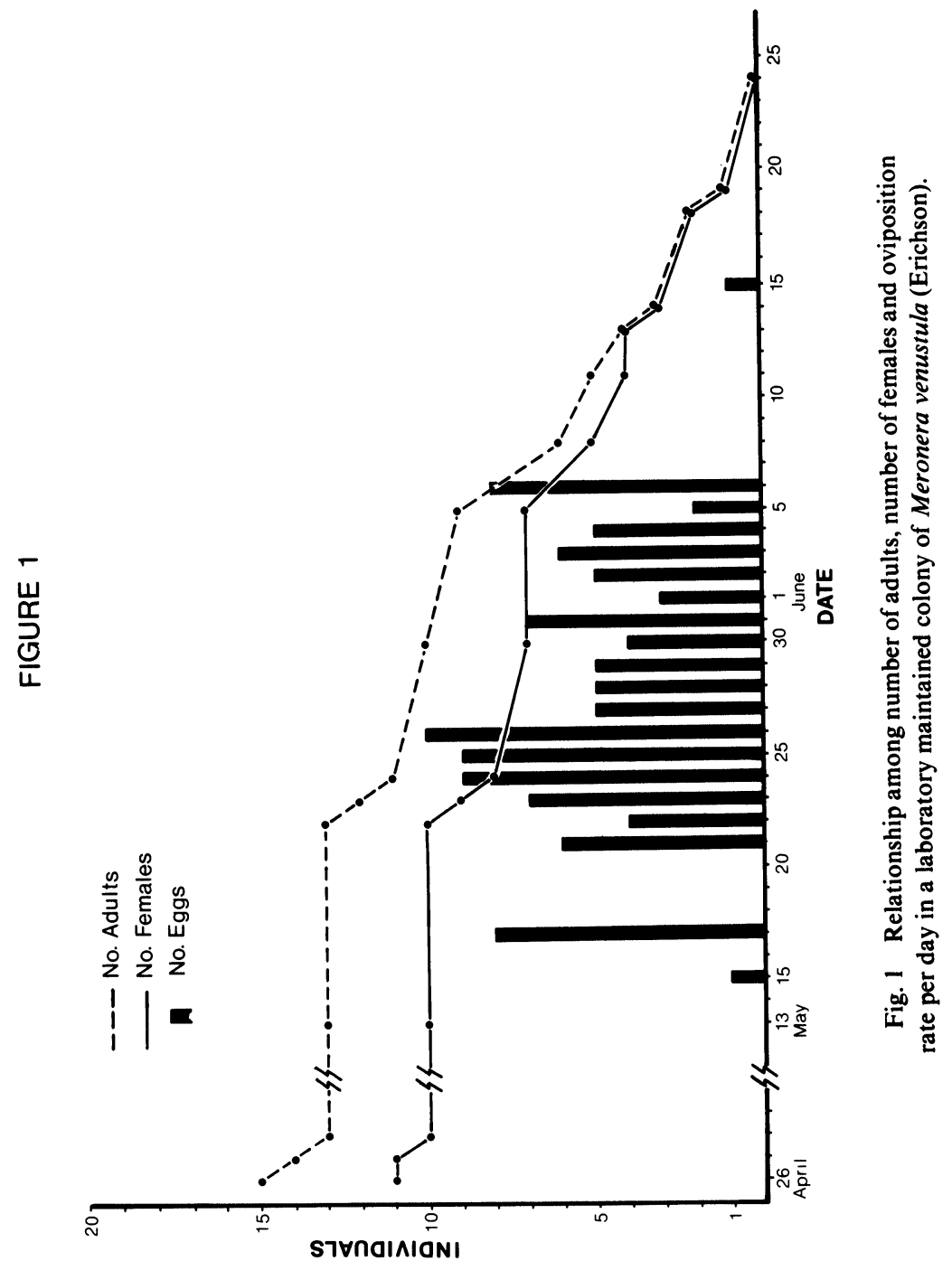


Total egg production over life of the colony was 104 . From the time of first egg laying until cessation of oviposition was 25 days with 1 egg laid 9 days later. Most eggs (91\%) were produced during a period of 17 days between May 21 and June 6. From time of first oviposition until egg production decreased to zero (June 6), an average of 4.3 eggs were laid per day. Based on an average of 8.5 females alive during this period, average egg production per female per day is 0.51 . There were, however, 4 days in which more eggs were deposited over a 24 hour period than there were females alive during that period. This occurred on May 24 (8 females: 9 eggs), May 25 (8 females: 9 eggs), May 27 (8 females: 10 eggs) and June 6 (7 females: 8 eggs). On these dates it is necessary that at least one female had laid 2 eggs during a 24 hour period. The average total number of eggs per female over the entire oviposition period is 12.1 (based on an average of 8.5 females alive during this period).

Fertility of eggs laid by $M$. venustula was very high. Only 2 eggs failed to hatch out of $\mathbf{5 2}$ observed closely, a fertility and/or hatching success of $96 \%$. Less detailed observations of other eggs suggests similar hatching success. It is interesting that the last egg laid was also fertile and hatched.

Adults survived an average of $\mathbf{4 3 . 5}$ days from the time of collection (May 26), with a maximum survival of 61 days. This then represents minimum life expectancy of adults under laboratory conditions. It is not known whether adult longevity under these conditions reflects survival in the field. Nor is it possible to determine how long adults had been active before they were collected. Possible factors that could cause survival of laboratory maintained colonies not to reflect natural longevity include increased survival due to more stable laboratory conditions or decreased survival due to build up of pathogens or inadequate and/or stressful conditions in artificial colonies.

\section{Development and Pupation}

Available developmental rates for eggs, all instars of larvae, and pupae are summarized in Table 1.

Eggs are white, ovoid and translucent and average $0.45 \times 0.35$ $\mathrm{mm}(\mathrm{N}=10)$. They were laid singly on the substrate with no apparent tendency to form clusters. Under conditions in the laboratory aver- 
Table 1. Developmental Rates of Eggs, Larval Instars, and Pupae of Meronera venustula (Erichson)

\begin{tabular}{llll}
\hline Stage & Duration & $\overline{\mathrm{x}} \pm$ S.D. & $\mathrm{N}$ \\
\hline Egg & $1-4$ days & $2.8 \pm 1.2$ & 17 \\
Instar I & $1-4$ days & $1.8 \pm 1.1$ & 9 \\
Instar II & $1-2$ days & $1.4 \pm 0.5$ & 7 \\
Instar III & $4-5$ days & $4.5 \pm 0.71$ & 2 \\
Pupae & $4-5$ days & $4.5 \pm 0.71$ & 2 \\
\hline
\end{tabular}

age duration of the egg stage was 2.8 days. The first instar lasted an average of 1.8 days, the second 1.4 days and the third 4.5 days. Survival of larvae beyond instar I was not good, especially during the latter stages of the study, during which laboratory temperatures fluctuated widely. It is not clear whether reduced survival of larvae was a result of temperature regime, temperature fluctuation or other inadequate environmental conditions. Only 2 larvae completed development to the adult stage though several other third instar larvae were killed for study.

Both larvae which reached the prepupal stage completed pupation without production of a cocoon. Production of a silken cocoon for pupation has been noted among a variety of aleocharine larvae (see Ashe 1982, Frank and Thomas 1984) and is presumed to be characteristic of members of this subfamily. Pupation of $M$. venustula larvae without production of a cocoon is therefore quite unexpected. One of the 2 larvae produced a thin, shiny deposit on which the pupa lay. In the other, no such deposit was observed. It is possible that this deposit represents a vestigial or poorly formed pupal cocoon, but this cannot be confirmed without additional observations.

Though these larvae did not form a pupal cocoon, it does not represent positive proof that larvae do not form a cocoon for pupation under natural conditions. A number of conditions in the laboratory cultures, including nutrition, humidity, temperature, substrate and others, may not have sufficiently approached natural conditions. Still, lack of a pupal cocoon is suggestive and deserves further investigation.

The form of pupal cuticular modifications may have a bearing on this problem. Examination of the pupal exuvia showed that the pupa of $M$. venustula is covered with a distinctive arrangement of very long, stiff cuticular spines. These spines are much more remi- 
niscent of the cuticular modifications found on pupae of many staphylinids (for examples see Paulian 1941, McCabe and Teale 1981) than they are the more scattered fine hairs found on most described aleocharine pupae (see, for example, Chamberlin and Ferris 1929, Ashe 1981). Crowson (1967) suggested that these large spines served to hold the body of the pupa in position in the pupal cell. Such spines would presumably not be required in aleocharine larvae which pupate within a silken cell. However, very little is known

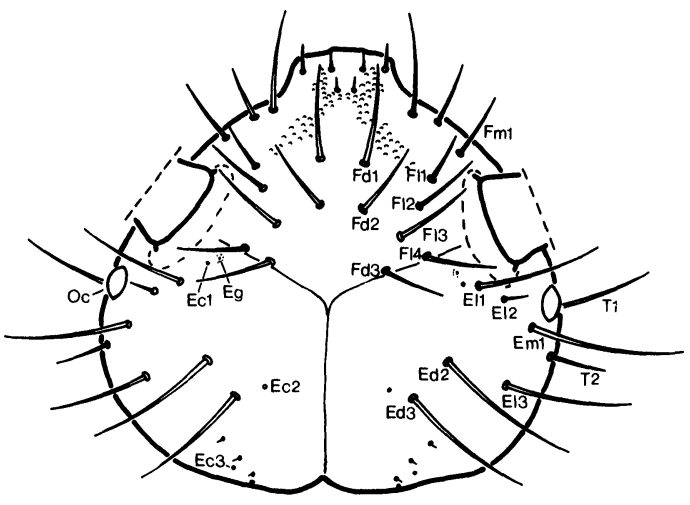

$0.1 \mathrm{~mm}$

2

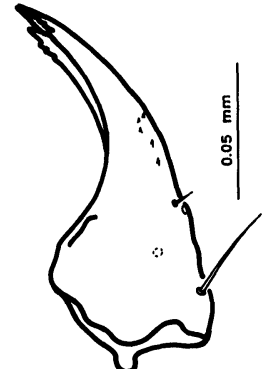

3
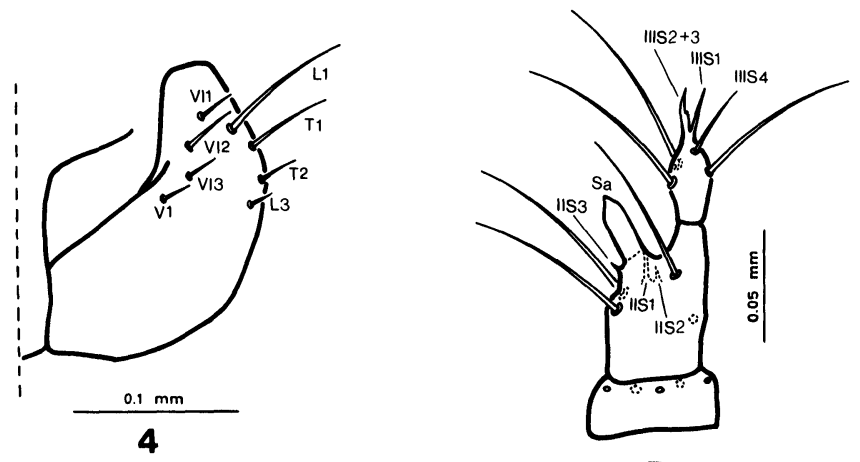

5

Figs. 2-5. Meronera venustula, larval instar III. 2, head, dorsal aspect; 3, mandible, ventral aspect; 4, head, ventral aspect; 5 , antenna, dorsal aspect. 
about aleocharine pupae, and few have been described. Therefore, discussions of possible differences in pupal structure or habits of pupation are presently based on very incomplete comparative information.

The total rate of development from hatching to fully mature larvae averaged 7.7 days with a maximum of 10 days at room temperature (described above). The pupal stage lasted an average of 4.5 days. Time required for development from oviposition to emergence of adult averaged 15 days. Adults which emerged were active and fed well, suggesting that more than one generation per year is possible.

Oviposition rates, fecundity and developmental rates observed for $M$. venustula in the laboratory cultures provide a base line of information about the group. However, average daily temperature under natural conditions, especially in the wet detritus where adults were collected early in the spring, are almost certainly much lower. It is likely that this would lead to much slower developmental rates, and perhaps retardation of other physiological functions associated with fecundity, than those reported in this study.

\section{DESCRIPTION: LATE INSTAR LARVA OF MERONERA VENUSTULA}

(Figures 2-16)

(Chaetotaxic nomenclature according to Ashe and Watrous 1984)

General: Length of mature larva $2.2-2.7 \mathrm{~mm}$. Head width about $.29-.23 \mathrm{~mm}$. Antennal length about $.14 \mathrm{~mm}$. General body form elongate, more or less flattened, parallel sided and very slightly tapered to apex in apical half of abdomen. Color of mature larva white with slight greyish cast, especially on head and apical abdominal segments. Microsculpture absent except for distinctive patches of small dome-like microsculpture on frontal and clypial regions of head and short rows of microspinules medially on abdominal segment VIII. Vestiture of scattered long simple setae.

Head: (Figures 2, 4) Length to width ratio 0.9-1.0. Ocellus single on each side, small. Ecd ysial sutures distinct, lateral arms attaining antennal fossae. Chaetotaxy as in Figures 2, 4; frontal region with all normal setae present, campaniform sensillae absent; epicranial region with Edl absent, epicranial lateral row complete with setae E11-3, E12 much smaller than E11 or E13, epicranial marginal row with Em2-3 absent, epicranial campaniform sensillae Ecl-3 


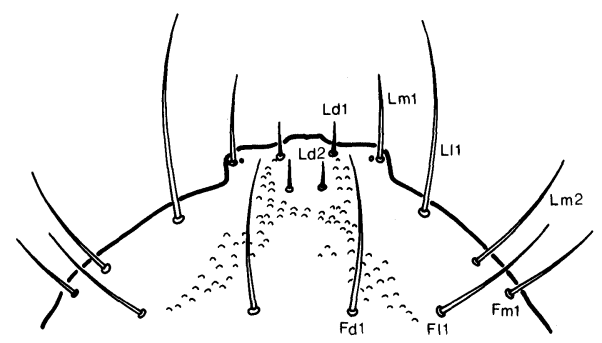

$\frac{0.05 \mathrm{~mm}}{6}$
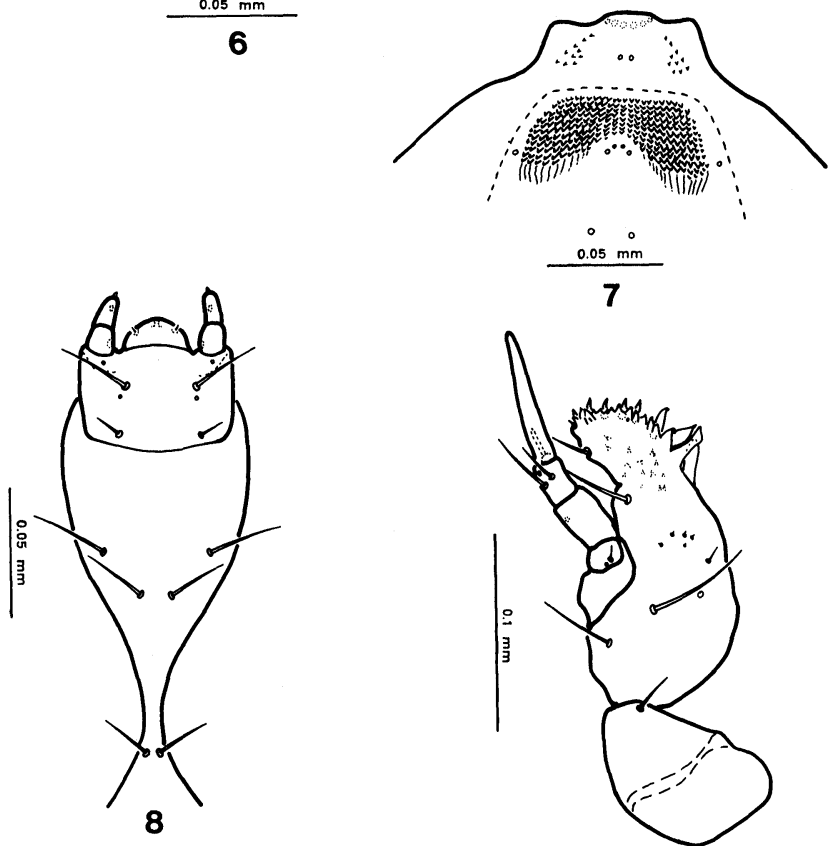

9

Figs. 6-9. Meronera venustula, larval instar III. 6, labrum and antero-frontal region of head, dorsal aspect; 7, labrum, adoral aspect (epipharynx); 8, labium; 9, maxilla, dorsal aspect.

present, posterior epicranial setae P1-4 present, microspinose; temporal region with setae T1-2 present, T1 ventral to ocellus, T1 larger than $\mathrm{T}$; lateral region with lateral seta $\mathrm{L} 2$ absent, $\mathrm{L} 1$ much larger than L3; ventro-lateral setae V11-3 present; ventral seta V1 present; campaniform sensillae of lateral and ventral regions absent. 
Antenna as in Figure 5; three articled, antennomere 1 transverse, about 2.5 times as wide as long, with 5 campaniform sensillae equidistant around apex; article 2 about 2.9 times as long as 1, constricted apical portion about $0.24-0.25$ times length of 2 ; article 3 about 0.5 times length of 2; sensory appendage of antennomere 2 inflated, more or less parallel sided and obtusely and bluntly pointed, about 1.8-1.9 times length of constricted portion of antennomere 2; antennomere 2 with solenidia IIS1-3 present, IIS1 more or less digitiform, slightly tapering to obtusely rounded apex, about 0.5-0.6 times length of sensory appendage, IIS2 spinose, about 0.3-0.4 times length of IIS1, IIS3 very small, spinose; solenidia of antennomere 3 with IIIS1 setose, as long as IIIS2+3, IIIS2 and IIIS3 fused, IIIS2 present as slight projection on side of IIIS3; IIIS4 setose. Labrum as in Figure 6; not separated from head capsule by a suture; anterior margin protruded as broad, truncate, parallel sided lobe; with dome-like microsculpture medially and latero-medially; not divided by sutures into distinct sclerotized areas; all normal setae present, setiform, Ld1 and Ld2 small, Ld1 larger than Ld2, other labral setae larger. Epipharynx as in Figure 7; with patch of densely arranged, well developed rows of spines medially. Mandibles (Figure 3) curved apically, flattened and broad internally, without molar lobe basally; internal tooth in dorso-ventral plane, forming a distinctly bilobed apex to mandible with ventral tooth larger than dorsal tooth, edges of apical teeth serrate; 2 setae present externally in basal half, more proximal seta much larger than very small distal seta. Maxilla (Figure 9) with cardo broadly oval, incompletely divided medially by internal sclerotized ridge, with moderate seta on antero-lateral margin; stipes rounded at base, not distinctly separated from mala by suture; mala (Figure 9) with apex oblique, adoral surface with several setae and numerous blade-like cuticular spines, proximal seta blade-like, proximal spine thickened, longer than wide, blunt at apex; mala with 2 large setae near lateral margin, dorsal surface with scattered, minute cuticular spines; maxillary palpus (Figure 9) of three articles and palpifer consisting of cresentric sclerite at base of palpus, surface of palpifer with 1 seta and 1 campaniform sensilla, article 11.3 times as long as 2 , article 3 1.4 times as long as 2 and 3 together, article 3 with small digitiform sensory appendage on external surface. Labium (Figure 8) consisting of premental and fused mental-submental sclerites; ligula transverse, about 2.5 times as long as wide, broadly rounded apically; 
labial palpus 2 articled, article 2 about 1.2 times length of 1 ; seta on mentum near base of labial palpus large.

Thorax: Pronotum as in Figure 10; anterior row of setae with A1-5 present, A1, A3 and A5 very small; lateral setae wih L1-5 present, L3 very small, L5 displaced medially to near C3, L5 very small; posterior setae P1-5 present; discal setae reduced, represented only by $\mathrm{Da} 2$ and $\mathrm{Dc} 2$, Da2 very small, Dc2 very large; campaniform sensilla $\mathrm{Cl}$ present or absent, very small if present, $\mathrm{C} 2$ and $\mathrm{C} 3$ present, $\mathrm{C} 4$ present postero-lateral to $\mathrm{Dc} 2, \mathrm{C} 5$ absent, $\mathrm{C} 6$ present. Mesonotum (Figure 11) with lateral setae represented by L1, L2 and L4, L1 slightly medial to L2; posterior setae P1-5 present; discal setae $\mathrm{Da} 2$ and $\mathrm{Dc} 2$ present, of similar size; campaniform sensillae C3, C4 and C6 present. Metanotum similar to mesonotum. Legs as in Figure 14; chaetotaxy characteristic of subfamily (see Ashe and Watrous 1984), rather long and slender, femur 3.0-3.1 times as long as greatest width, tarsungulus long and slender.

Abdomen: Abdominal tergum I (Figure 12) with lateral setae $\mathrm{L} 1$ and L4 present, posterior setae P1-5 present; discal setae Da2 and Dc2 present, minute; campaniform sensilla C6 present. Abdominal terga II-VII (Figure 13) similar to abdominal tergum I except Da2 absent and additional very large seta (here interpreted to represent $\mathrm{Db} 2$ ) present in posterior row between $\mathrm{P} 2$ and $\mathrm{P} 3$, campaniform sensillae $\mathrm{C} 4$ and $\mathrm{C} 6$ present, $\mathrm{C} 4$ displaced posteriorly to near posterior row between $\mathrm{Db} 3$ and P3. Abdominal tergum VIII (Figure 15) not prolonged posteromedially in association with tergal gland structures; lateral setae $\mathrm{L} 1$ and L4 present; posterior setae P1-5 present, $\mathrm{P} 1$ reduced to pore, $\mathrm{P} 2$ and $\mathrm{P} 4$ very large; $\mathrm{Pa} 1$ present, very small, microsetose; discal setae Dc2 present, Da2 absent; campaniform sensillae C5 and C6 present. Tergal gland reservoir indistinct, completely membranous, about 0.7 times length of tergum VIII; gland ducts terminating in small, round papillate sclerotized structures attached to reservoir sac (Figure 15). Abdominal terga IX-X as in Figure 16; urogomphus single articled, short, about 0.3-0.4 times length of tergum IX. Hooks of pseudopodium 4, reduced, very small to minute (Figure 16).

Diagnostic Features and Discussion. Larvae of $M$. venustula are particularily distinctive and can be distinguished from those of other aleocharines by the combination of: fusion of labrum with head and distinctive patches of dome-like microsculpture on labrum 

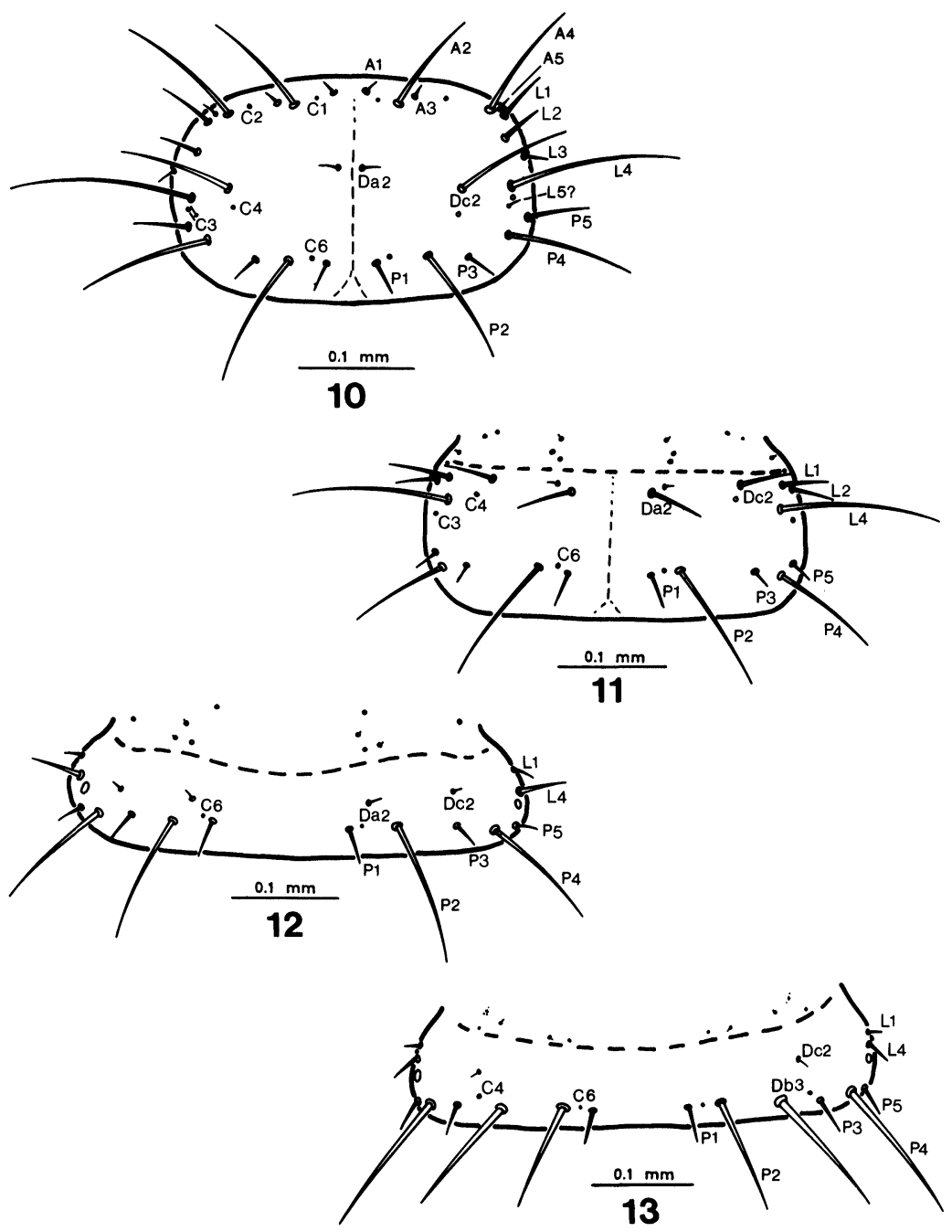

Figs. 10-13. Meronera venustula, larval instar III. 10, pronotum; 11, mesonotum; 12, abdominal tergum I; 13 abdominal tergum II.

and anterofrontal margins of head (Figure 6); distinctive structure of the maxilla (Figure 9); short, broad ligula (Figure 8); apically bifid mandibles (Figures 3); sensory appendage of antennomere 2 inflated, parallel sided and obtusely pointed apically (Figure 5); 
fusion of solenidia IIIS2 and IIIS3 of antennomere 3 (Figure 5); pronotal chaetotaxy with discal setae represented only by $\mathrm{Da} 2$ and Dc2, and Dc2 very large in comparison to Da2 (Figure 10); abdominal terga II-VII with 3 long setae (P2, Db3, P4) in posterior row (Figure 13); completely membranous and indistinct tergal gland reservoir, without associated external modification of posteromedial margin of tergum VIII (Figure 15), and small, papillate sclerotized termination of gland ducts; and, 4 very small to minute anal hooks of the pseudopodium (Figure 16).

The description provided here highlights and illustrates the distinctive characteristics of larvae of Meronera venustula in comparison to other known aleocharine larvae. Nomenclature and abbreviations for chaetotaxic structures are those developed by Ashe and Watrous (1984). Presumed homologies of setae are based on relative positions in relation to other more stable chaetotaxic features which provide reference points as proposed by these authors. The possibility of incorrect designation of homologous setae remains (for example, note problems associated with designation of Db3 of abdominal terga II-VII). However, usefulness of a general reference system for naming and discussing setae is apparent in spite of this limitation. Such errors in designation and weaknesses inherant in the system can only become clarified after chaetotaxy of larvae of a significant number of aleocharine taxa have been studied comparatively and in detail. Inaccuracies which can result from this approach are discussed in Ashe (In press) and are recognized here.

Though the relatively reduced chaetotaxy of larvae of $M$. venustula causes problems in determining homologies of some setae, most are readily homologizable with comparable chaetotaxic features of Atheta coriaria Kroatz (see Ashe and Watrous 1984). However, some are problematic and require additional discussion of rationale and alternative possibilities. Head setation (Figures 2,4 ) is similar to that described for Atheta coriaria (Ashe and Watrous 1984). It differs primarily in that one seta is absent from the epicranial dorsal row and one is absent from the lateral row. These missing setae are respectively determined to be Edl, based on position of $\mathrm{Ed} 2$ and $\mathrm{Ed} 3$ in relation to $\mathrm{Ec} 2$, and $\mathrm{L} 2$, based on position of remaining lateral setae in comparison to other rows of setae. Labral setae are initially difficult to identify because of absence of sutures which delimit the labrum from the head capsule; however, once frontal setae are identified, homologies of labral setae become apparent. 

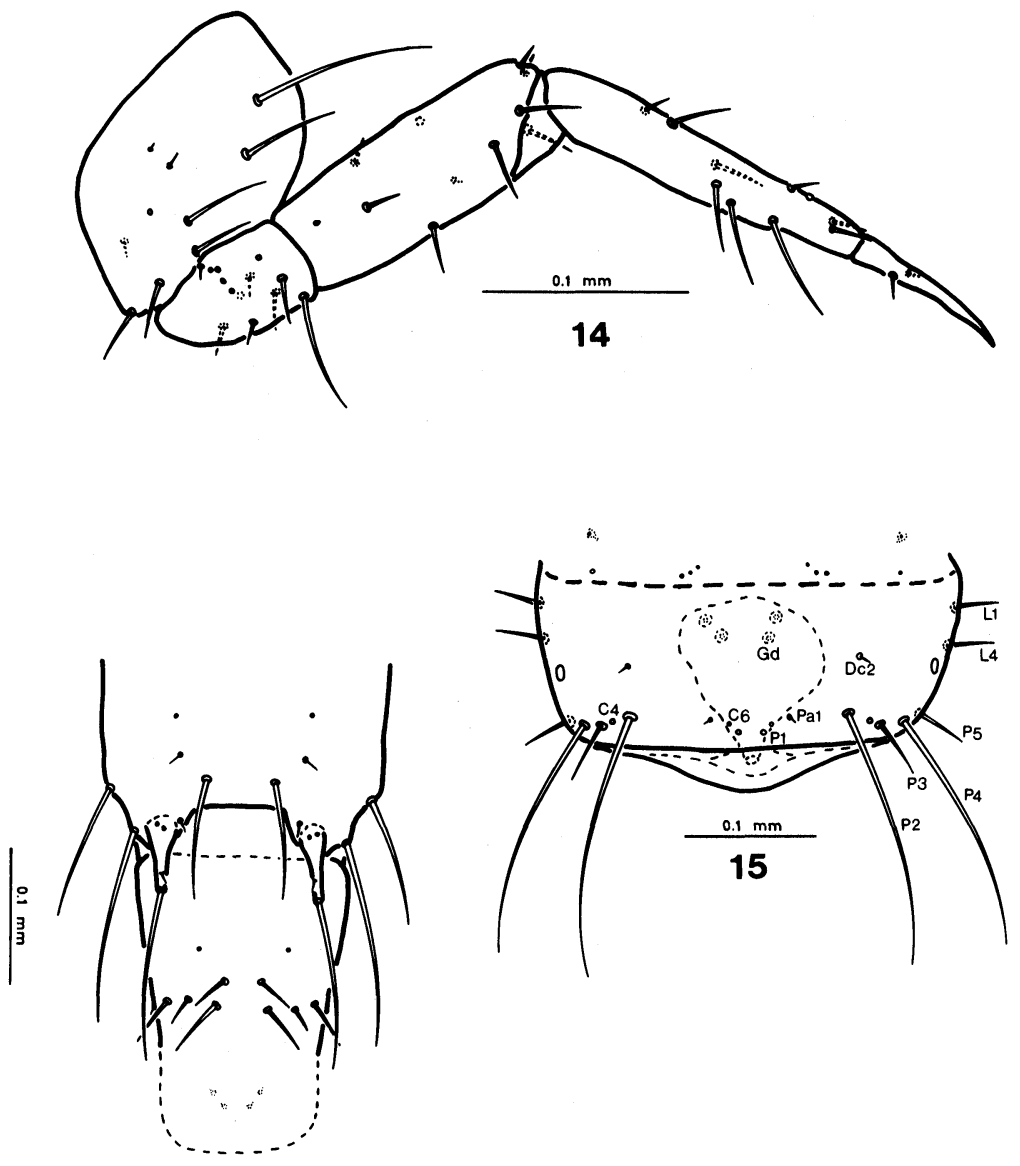

16

Figs. 14-16. Meronera venustula, larval instar III. 14, left proleg, anterior aspect; 15 , abdominal tergum VIII with outline of gland reservoir and sclerotized portions of gland ducts; 16, abdominal terga IX-X.

Antennomere solenidia IIIS2 and IIIS3 appear to be fused for almost their entire length (Figure 5). A small projection on the lateral side of the more internal solenidium of antennomere 3 is interpreted to represent a vestigial IIIS2 based primarily on its' position in relation to other solenidia. 
Discal setae of the pronotum are reduced to a medial and a lateral seta on each side. These are interpreted to represent $\mathrm{Da} 2$ and $\mathrm{Dc} 2$ respectively. Identity of the very small pronotal seta postero-medial to campaniform $\mathrm{C} 3$ is problematic (Figure 10). It is here interpreted to represent lateral seta L5 which is displaced medially; however, it could be homologous to a discal seta and L5 may be absent. The first medio-lateral seta of the mesonotum is interpreted to represent Ll even though it is more mesal than the usual position of L1 (Figure 11). Because of the relatively discal position of this seta, an alternative possibility is that it is actually $\mathrm{Dd} 2$.

Interpretation of the posterior row of setae of abdominal terga II-VII is complicated by presence of a large seta between P2 and P3

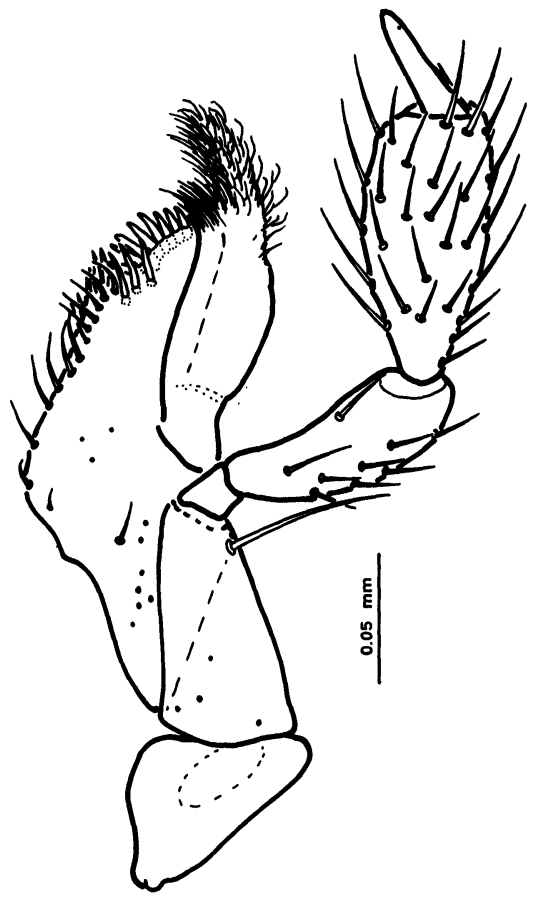

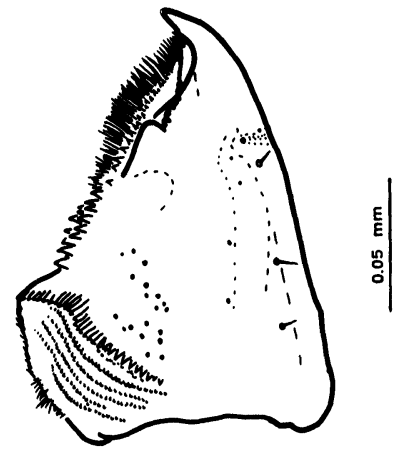

18

17

Figs. 17-18. Meronera venustula, adult mouthparts. 17, maxilla, dorsal aspect; 18 , right mandible, dorsal aspect. 
(Figure 13). This is very tentatively interpreted to represent Db3 (consistent with Ashe and Watrous (1984)), but the homologies of this seta are uncertain. Similarly, the campaniform sensilla between Db3 and P3 on abdominal terga II-VII is interpreted to represent $\mathrm{C} 4$ which has been displaced posteriorly, rather than C5. This is based on the facts that C5 is not found on other terga, and C5 is located between P3 and P4 in all other aleocharine larvae which have been examined for this characteristic. However, this sensilla could actually represent $\mathrm{C5}$ which has been displaced into an aberrant position.

Resolution of these and other problematic chaetotaxic homologies will hopefully be facilitated by future comparative studies of larvae of both closely related and more distantly related aleocharines.

The tergal chaetotaxy of larvae of $M$. venustula is reduced to a pattern very suggestive of that described by Ashe (In press) for larvae of the fungus feeding Gyrophaenina. However, there are significant differences between members of these groups in mouthpart structure of both larvae and adults as well as other gross body differences. In addition, structure of the tergal gland and associated structures differ in significant ways. Based on these very striking differences between Meronera larvae and those of the Gyrophaenina, similarities in tergal chaetotaxy of larvae of these two groups are almost certainly derived in parallel and do not indicate a close relationship.

\section{ConClusions}

Several general features of the life history and ecology of Meronera venustula are suggested by this study. Presence of adults (and absence of larvae) in early spring implies that adults are the overwintering generation. This is consistent with a similar report of Blatchley (1910); however, he did not give data to support his statement. Available data do not preclude the possibility that pupae or prepupal larvae overwinter and emerge to adults in spring. However, absence of tenerals from among adults collected is not consistent with this interpretation.

The sex ratio in the early season adult population appears to be strongly biased toward females ( 11 females: 4 males in this sample). It is possible that this represents a collecting artifact. If, however, 
this reflects a true population sex bias then such an unusual sex ratio could result from several factors, including, but not limited to, differential production of sexes at zygote level, differential survivial of sexes of larvae, or differential survival of sexes in overwintering adult populations. It would be interesting to determine if the proportion of sexes in the population is equalized as the season progresses.

There is a significant preoviposition period between the time adults emerge from hibernation and the time egg laying begins. This period lasted at least 20 days in laboratory cultures at $22-25^{\circ} \mathrm{C}$. The probability that this period is not simply a result of delayed egg laying under unnatural conditions is indicated by the fact that no larvae were found in the field through at least May 3, 1984 when he last field sample was taken. Topp (1975a) noted that preoviposition of Atheta fungi (Gravenhorst) is temperature dependant but is also influenced by photoperiod. These factors probably also have a similar effect on specimens of $M$. venustula.

Developmental time of $M$. venustula averaged 15 days from oviposition to adult and is relatively short among known developmental times of aleocharine larvae. However, the larval period of 7.7 days is much longer than the 3.2 days of the mushroom inhabitating aleocharine, Phanerota fasciata (Say) (Ashe 1981). Among aleocharines which have more generalized habits, Topp (1971) found that preimaginal development of Atheta sordida Marsham required an average of 31 days at $23^{\circ} \mathrm{C}$ and (1975a) that Atheta fungi requires 40 days at $16^{\circ} \mathrm{C}$. Topp also $(1975 \mathrm{a}, 1975 \mathrm{~b})$ noted the purely temperature dependent relationship between development of eggs, larvae and pupae of athetine aleocharines. It is reasonable to expect that development of $M$. venustula is similarly temperature dependent. Adults, and also larvae later in the season, would certainly be living under much lower average, and probably lower maximum, temperatures than those which they experienced under laboratory conditions. If true, then preimaginal development as well as such temperature influenced physiological processes such as preoviposition period and oviposition rates, would be much slower under natural conditions than those reported here.

Topp (1975b) also noted a relationship between survival of larvae and temperature. He found that most athetine larvae developed with less mortality at $16^{\circ} \mathrm{C}$ than at higher temperatures. He also found that larvae of Bolitochara lunulata Paykull were consistently 
deformed if they emerged from eggs which had developed at $23^{\circ} \mathrm{C}$, and suggested that they should be reared at lower temperatures. These results provide support for the suggestion presented above that the relatively high laboratory temperatures, with occasional fluctuations to near $30^{\circ} \mathrm{C}$, was primarily responsible for decreased survival of larvae in this study.

It seems apparent that females of $M$. venustula mature only a single egg at a time. In laboratory cultures eggs were laid at an average rate of about 1 every other day per female, though rarely 2 eggs were produced by a single female in a 24 hour period. These averages were taken under the assumption that all females in the cultures were equally successful at maturing eggs, an assumption that cannot be evaluated further. However, eggs are relatively large (.45 mm average length compared to a maximum adult length of 2.2 $\mathrm{mm})$. Therefore, a substantial investment of a female's energy resources are put into egg production, especially so when one considers that an average of 12.1 eggs were produced per female over a 26 day period (most in 17 days, see fecundity above). The fact that females were able to mature eggs at this rate suggests that they were receiving adequate nourishment from the food and fungal hyphae on which they fed. This is not to suggest, however, that these egg maturation rates can uncritically be assumed to represent those rates under natural conditions. Still, they must reflect natural oviposition rates at some level.

Time of oviposition, developmental rate of preimagos, and adult longevity suggest that $M$. venustula may be multivoltine with potential overlap of generations under natural conditions.

One of the most interesting findings of this study is that at least adults, and probably larvae also, will actively feed on fungus mycelium and appear to get a significant proportion of their nutrition from this resource. It is not possible to infer from available evidence that individuals of $M$. venustula are primarily fungus feeders under natural conditions. However, several lines of circumstantial evidence, in addition to observations of adults grazing on fungus mycelium, suggest that these beetles have feeding habits somewhat different from most other aleocharines. These include: 1) other aleocharine adults kept in culture under conditions similar to those of $M$. venustula showed no inclination to graze on fungus mycelium; 2) cannibalism of eggs or dead adults did not occur in cultures of $M$. venustula as it did in other cultures of aleocharines, suggest- 
ing that generalized predatory inclinations are not strongy devel oped; and 3) large amounts of fungus mycelium was present in guts of some adults and larvae.

Though structural characteristics of mouthparts of larvae and adults of $M$. venustula are not as highly derived in association with fungus feeding as are those of the mushroom inhabiting Gyrophaenina (see Ashe 1984 and In press), several features of mouthparts of adults and larvae are similar to those found among known fungus eating beetles. These also suggest that they have somewhat different feeding habits from many other aleocharines which are believed to be more general predators.

Mouthpart characteristics of larvae which suggest that observations of fungus feeding are not aberrent include the apically bifid mandibles which are broadly concave internally (Figure 3 ), the large dense patch of spines on the epipharynx (Figure 7) and perhaps the short broad ligula (Figure 8). Features of adults which suggest fungus feeding include the prominent ridge of distinct teeth with rows of smaller teeth more basally in the molar region of the mandible (Figure 18). Seevers (1978) and Ashe (1984) have suggested that such teeth in the molar region of mandibles of aleocharines are probably usually associated with fungus feeding. Preliminary observations of habits of several aleocharine species which have this characteristic (unpublished data) have supported this contention. However, it is interesting that maxillae of adults of adults of $M$. venustula (Figure 17) are not noticably modified from the generalized aleocharine condition. Among the fungus feeding Gyrophaenina it is the maxilla which is most strikingly developed in association with this habit. It is, however, important to note the different fungal resource that is being used by gyrophaenines, which feed on the hymenium layer of fruiting bodies of agarics, and members of $M$. venustula which apparently feed primarily on fungal hyphae. In any instance, these structural characteristics of adult and larval $M$. venustula are consistent with the habit of fungus feeding. However, they are also consistent with general omnivory or detritivory, and these habits cannot be eliminated as the generalized feeding mode in this species.

The weight of evidence suggests that both adults and larvae of $M$. venustula feed on fungus mycelium or fruiting structures which would be abundant in the wet vegetable litter in which they live. However, though they were able to effectively feed on fungus myce- 
lium in laboratory cultures, they may eat it only facultatively under natural conditions.

Newton (1984) noted that species in several genera of aleocharines have been implicated as mycophagous. However, with the exception of the Gyrophaenina, fungus feeding by members of any aleocharine species had not been demonstrated. In general, this unexpected feeding habit of specimens of $M$. venustula suggests that fungus feeding, and perhaps other specialized feeding habits, may be more widespread within the Aleocharinae than has been expected in the past.

\section{ACKNOWLEDGMENTS}

I extend special thanks to Mr. James Day, an Antioch WorkStudy student in the Division of Insects at the Field Museum during the spring and early summer of 1984 , for his interest and commitment while caring for cultures of Menonera venustula and a number of other aleocharines. He initially made many of the observations reported here and maintained records of activities of the colony.

\section{SUMMARY}

Information about feeding habits, oviposition rate, developmental rate and longevity of adults of Meronera venustula (Er.) is provided based on colonies maintaned in the laboratory. Adults, and probably larvae, were found to actively feed on fungus mycelium and apparently received a substantial proportion of their nourishment from this resource. A preoviposition period of at least 20 days was followed by a burst of egg laying activity during which 104 eggs were laid by 10 females in 31 days. Average duration of the egg stage lasted 2.8 days, the first instar 1.8 days, the second instar 1.4 days and the third instar 4.5 days at temperatures of $22-25^{\circ} \mathrm{C}$. Pupation occurred without production of a pupal cocoon, and the pupal stage lasted an average of 4.5 days. Development under natural conditions is expected to be slower than rates reported because of expected lower temperatures in the natural microhabitat of these beetles. Adults survived an average of 43.5 days and a maximum of 61 days from the time of collection.

Late instar larvae are described and illustrations of distinctive features are provided. 


\section{References Cited}

Ashe, J. S.

1981. Studies of the life history and habits of Phanerota fasciata (Say) (Coleoptera: Staphylinidae: Aleocharinae) with notes on the mushroom as a habitat and descriptions of the immature stages. Coleopterists Bulletin 35(1): 83-96.

1982. Evidence on the species status of Phanerota fasciata (Say) and Phanerota dissimilis (Erichson) (Coleoptera: Staphylinidae) from host mushroom relationships. Coleopterists Bulletin 36(2): 155-161.

1984. Generic revision of the subtribe Gyrophaenina (Coleoptera: Staphylinidae: Aleocharinae) with a review of described subgenera and major features of evolution. Questiones Entomologicae 20(3): 129-349.

In Press. Structural features and phylogenetic relationships among immatures of genera of gyrophaenine staphylinid beetles (Coleoptera: Staphylinidae: Aleocharinae). Fieldiana: Zoology. 126 manuscript pp., 29 plates, 106 figures, 3 tables.

Ashe, J. S. AND L. E. Watrous.

1984. Larval chaetotaxy of Aleocharinae (Staphylinidae) based on a description of Atheta coriaria Kraatz. Coleopterists Bulletin 38(2): 165-179.

BLATChLEy, W. S.

1910. An illustrated descriptive catalogue of the Coleoptera or beetles known to occur in Indiana. Nature Publishing Co., Indianapolis, Ind. $1355 \mathrm{pp}$.

Casey, T. L.

1906. Observations on the staphylinid groups Aleocharinae and Xantholinini, chiefly of America. Transactions of the Academy of Sciences of Saint Louis 16: 125-434.

Chamberlin, J. S. and G. F. Ferris.

1929. On Liparocephalus and allied genera (Coleoptera: Staphylinidae). PanPacific Entomologist 5: 137-143, 153-162, 5 figures.

Crowson, R. A.

1967. The natural classification of the families of Coleoptera. E. W. Classey, Itd., Hampton, Middlesex, England. 187 pp.

ERICHSON, W. F.

1840. Genera et species staphylinorum insectorum coleopterum familiae, pt. 2. Berlin. 401-954.

Fenyes, A.

1918-21. Coleoptera. Subfamily Aleocharinae. Genera Insectorum 173. Pasadena, Calif. 453 pp.

Frank, J. H. AND M. C. Thomas.

1984. Cocoon-spinning and the defensive function of the median gland in larvae of Aleocharinae (Coleoptera: Staphylinidae): A review. Questiones Entomologicae 20: 7-23.

McCabe, T. L. and S. A. Teale.

1981. The biology of Oxyporus lateralis Gravenhorst (Staphylinidae). Coleopterists Bulletin 35(3): 281-285. 
Newton, A. F., JR.

1984. Mycophagy in Staphylinoidea, pp. 302-353. In, Q. Wheeler and M. Blackwell, eds. Fungus-Insect Relationships: Perspectives in ecology and evolution. Columbia University Press, New York.

Paulian, R.

1941. Les premiers états des Staphylinoidea. Mémoires du muséum national d'Histoire naturelle (NS) 15: 1-361.

PeschKe, K.

1978. Functionsmorphologische Untersuchungen zur Kopulation von Aleochara curtula Goeze (Coleoptera: Staphylinidae). Zoomorphologie 89: 157-184.

SeEvers, C. $\mathrm{H}$.

1978. A generic and tribal revision of the North American Aleocharinae (Staphylinidae). Fieldiana: Zoology 71: 1-289.

ToPP, W.

1971. Zur Biologie und Larvalmorphologie von Atheta sordida Marsh. (Col., Staphylinidae) Ann. Ent. Fenn. 37(1): 85-89.

1973. Uber Entwicklung, Diapause and Larvalmorphologie der Staphyliniden Aleochara morens Gyll. und Bolitochara lunulata Payk. in Nordfinnland. Annales Entomologici Fennici 39: 145-152.

1975a. Morphologische Variabilität, Diapause und Entwicklung von Atheta fungi (Grav.) (Col., Staphylinidae). Zoologische Jahrbucher Abeilung fur Systematik 102: 101-127.

1975b. Zur Larvalmorphologie der Athetae (Col., Staphylinidae). Stuttgarter Beiträge zur Naturkunde, Ser. A (Biologie) 268: 1-23. 

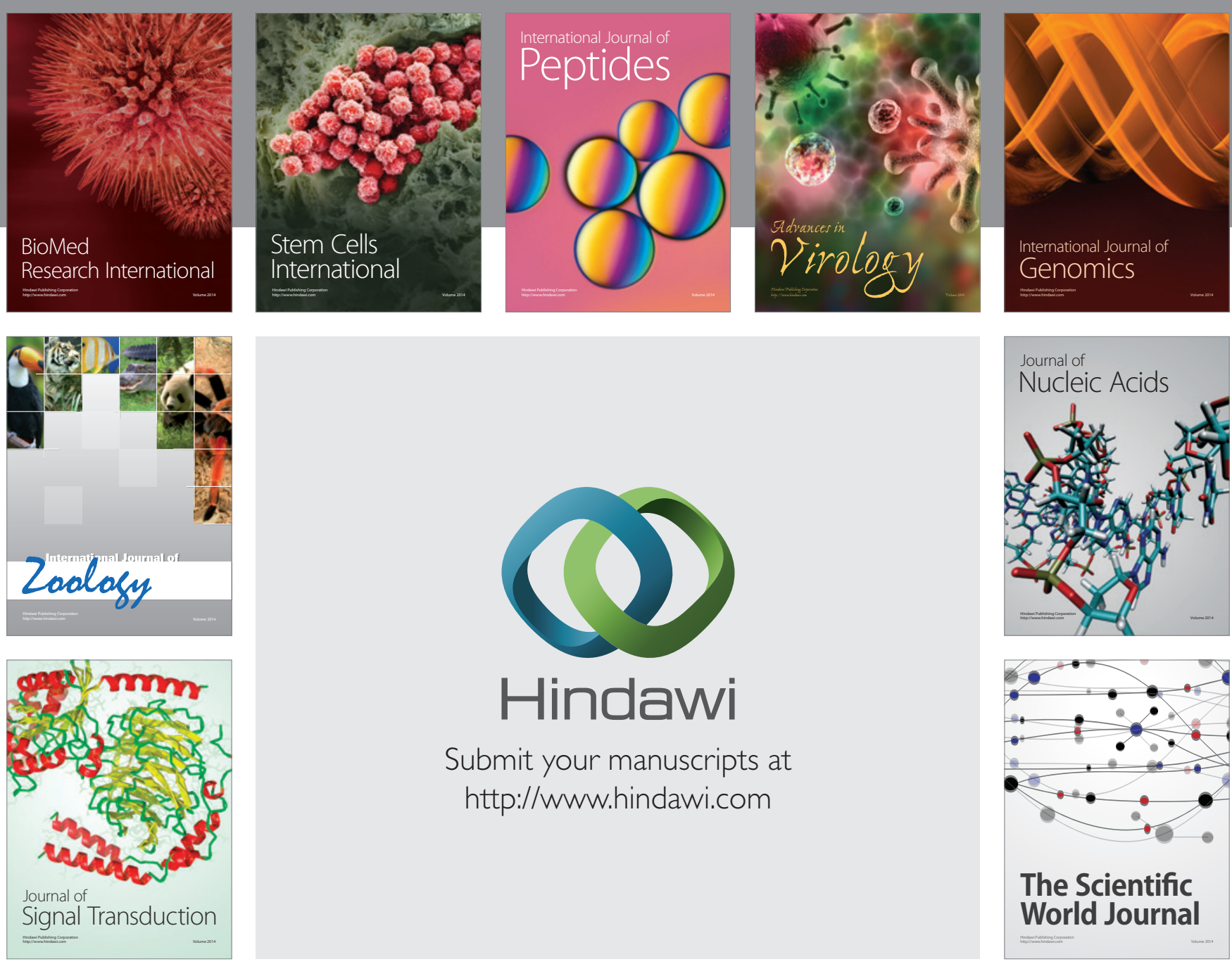

Submit your manuscripts at

http://www.hindawi.com
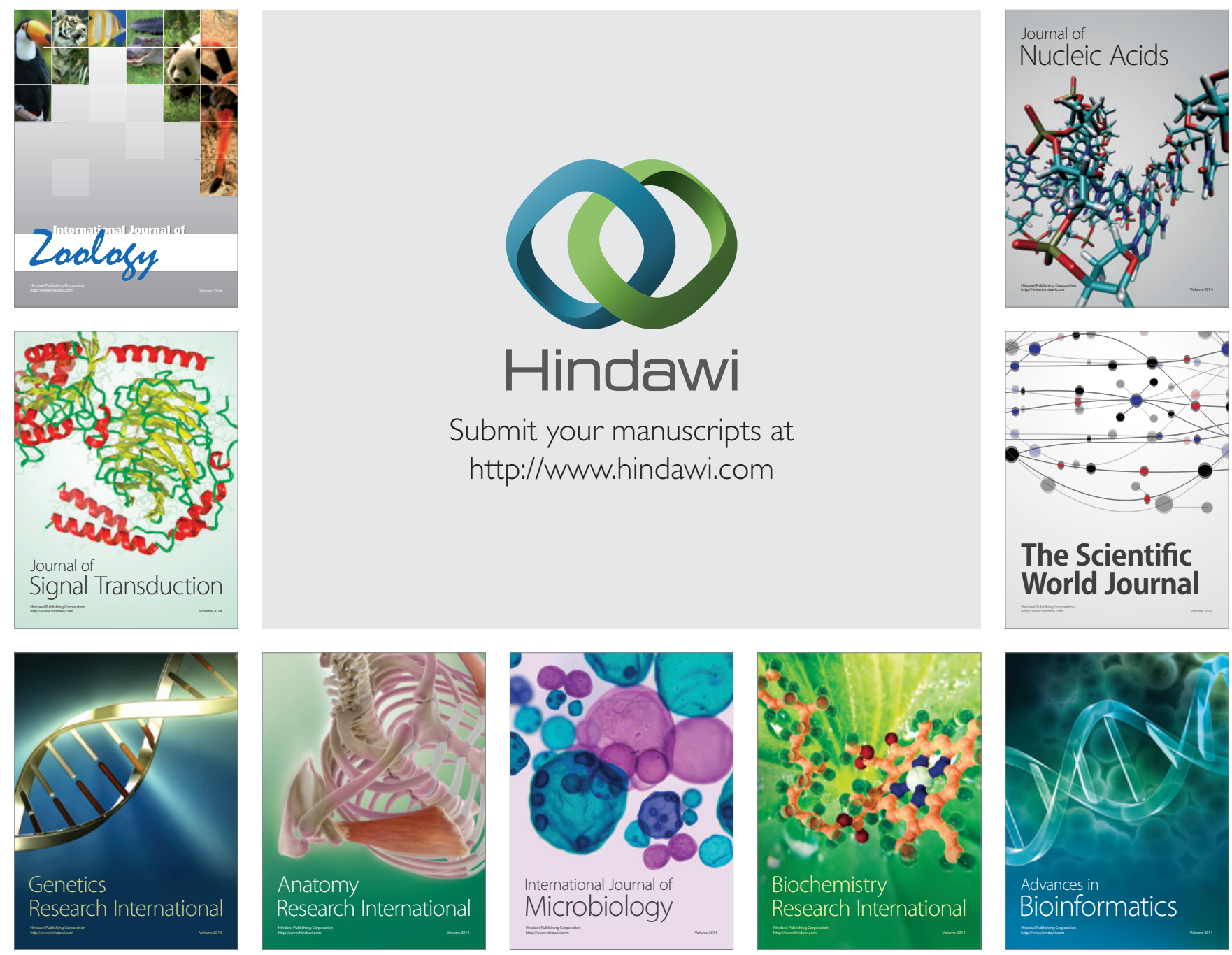

The Scientific World Journal
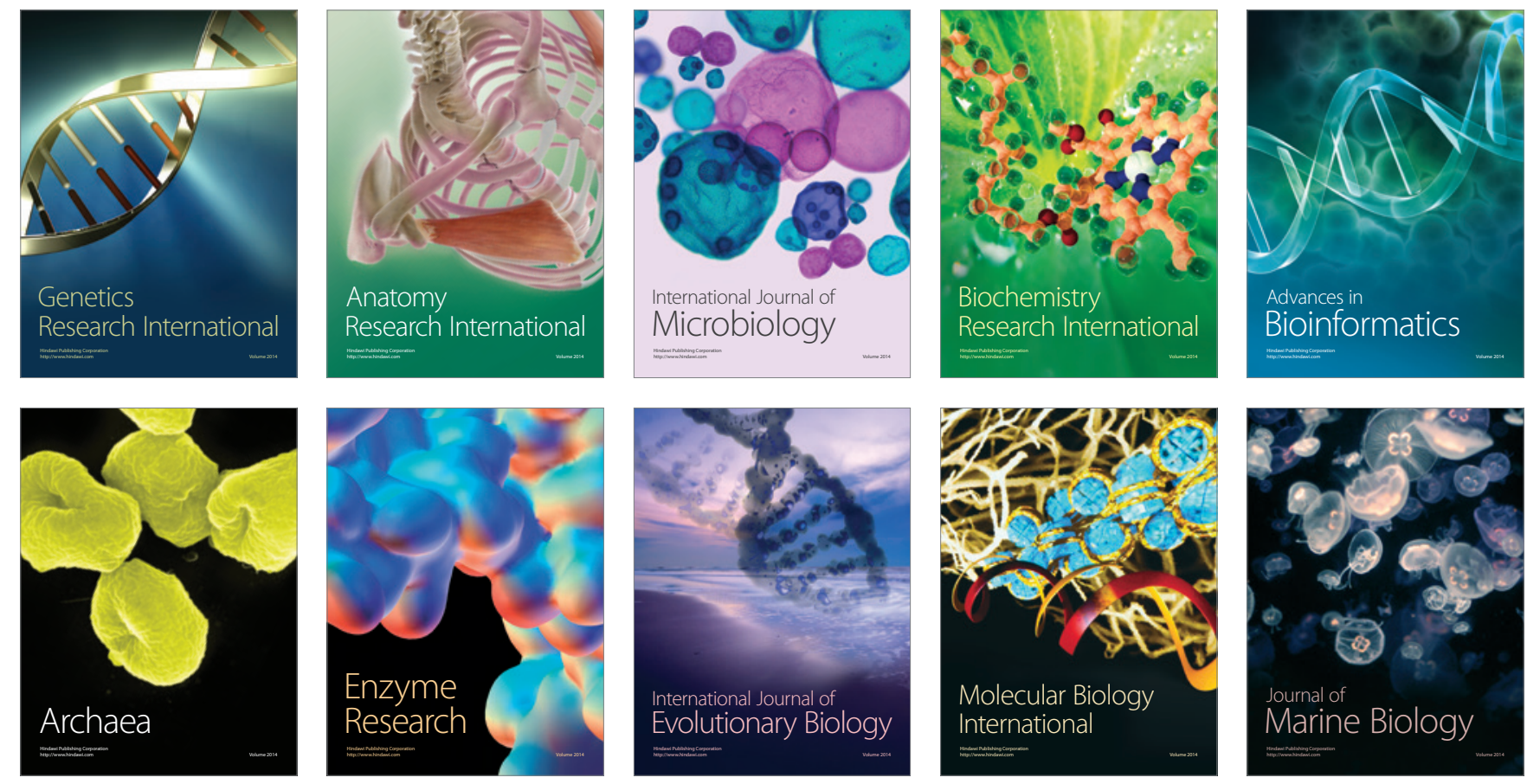